Julie Schablitsky

Kelly J. Dixon

Mark D. Leney

\section{Forensic Technology and the Historical Archaeologist}

Archaeological scholarship evolves, which means even the most progressive research is fleeting. Accordingly, the history of archaeology is riddled with innovative ways of explaining the past, and multiple, viable lines of interpretation can be pursued for any given archaeological site. In this intellectual climate, the array of interpretive possibilities and research directions in historical archaeology appear to be blossoming; however, the humanistic directions seem risky, at times idiosyncratic, and occasionally in need of scientific explanations (Delle 1999:136; Cleland 2001a:7, 2001b:30).

Incorporating forensic techniques and tests into research allows archaeologists to verify otherwise tentative interpretations and create tangible links among people, places, and things. The application of forensic technology to archaeological problems has already demonstrated that anthropologists can prove some of their interpretations beyond a reasonable doubt (Connor and Scott 2001). Today archaeologists can apply myriad forensic techniques to their work to answer questions and test hypotheses. In addition to standard skeletal analysis, archaeologists can recover nuclear and mitochondrial deoxyribonucleic acid (DNA) from artifacts and human remains, locate buried anomalies with remote sensing technology, and view artifacts spatially and microscopically to re-create historical events. This volume also demonstrates the successful expansion of the study of old and degraded DNA recovered from organic remains and visible stains, familiar to biological anthropologists as ancient DNA (aDNA), to include studies on DNA recovered from historic period personal artifacts. Julie Schablitsky (this volume) introduces the specialization of genetic archaeology, which is devoted to the recovery and analysis of DNA from artifacts, and its creative application to archaeological sites by incorporating DNA results with documents, material culture, and site structure. In order to launch genetic archaeology's application to historical sites, this prelude provides a brief overview of human DNA, along with its extraction and recovery techniques, before introducing the articles contained herein.

\section{Nuclear DNA and Mitochondrial DNA}

The human genome consists of nuclear and mitochondrial DNA. Nuclear DNA is present in 23 pairs of chromosomes within the nucleus of each cell, with a paternal and maternal chromosome inherited from each parent. Sex cells (sperm and eggs), contain only a single genome copy that consists of a recombined patchwork of genes of both paternal and maternal origin. Archaeologists and other research scientists use genomic nuclear DNA to reveal a person's sex, allelic profile, and rare allele variants in skeletal and now artifactual samples. In addition, nuclear DNA provides information that makes it possible to determine the number, the sex, and possibly the ancestral origins of people who came into contact with a particular artifact. Limitations of nuclear DNA include its short shelf life, having just two copies per cell, and the difficulty in showing direct ancestor/descendant relationships over many generations.

Although nuclear DNA exists in the nucleus of the cell, DNA containing different genetic information can also be found within a cell's mitochondria. As few as one or as many as several hundred mitochondria may exist within each cell. Mitochondrial DNA (mtDNA) is solely inherited from one's mother. Sperm contain mitochondria, but only the female's eggwith rare exceptions-contributes mitochondria to the new individual. Since copies of genetic information are stored in each mitochondrion, scientists have a better chance of recovering intact mtDNA than nuclear DNA with just two copies in the nucleus. In consideration of this fact, studies of ancient mtDNA have met with greater success, and consequently biological anthropologists focus their research on the 
extraction of mtDNA rather than nuclear DNA from ancient organics (Herrmann and Hummel 1994:3).

Historical archaeologists have an advantage over their prehistorian colleagues in human DNA recovery. By definition, the material studied by historical archaeologists is less ancient, thereby decreasing the number of times artifacts encounter temperature fluctuations and exposure to moisture between the moments of deposition and recovery. An additional benefit of working with the recent past is the relatively easy access to and availability of living descendant communities that can readily provide referential information for mtDNA analysis.

\section{DNA from Archaeological Contexts}

Following the advances of their colleagues in molecular biology, bioarchaeologists have been extracting degraded DNA for the last two decades (Herrmann and Hummel 1994; Jones 2001:14). The "molecular blueprint" for all life on earth can survive in fragments on archaeological sites (Jones 2001:10). DNA begins to degrade rapidly after cell death occurs, unless physical and/or biological processes such as freezing or desiccation intervene to maintain the physical integrity of the DNA-containing materials (Handt et al. 1994; Monsalve et al. 2002). For the most part, DNA is vulnerable to environmental conditions such as ultraviolet radiation, moisture, temperature fluctuations, and soil acidity. Although aged DNA breaks down over time, scientists have successfully recovered DNA from human bone thousands of years old (Herrmann and Hummel 1994:1-3) and from personal artifacts older than 125 years (Dixon this volume; Schablitsky this volume). Archaeologists should be encouraged and excited by the potential of forensic applications to their sites and materials, but caution must always be exercised when merging scientific disciplines.

\section{Contamination}

Contamination of DNA samples can be detrimental to a researcher's results. Although contamination can occur in both the field and laboratory, it is possible for archaeologists to protect their samples by taking certain precautions. In order to reduce the chances of contaminating artifacts and organic material, it is first necessary to anticipate the potential for contaminants at the site. Field personnel should be taught to identify potential candidates for DNA testing and how to protect samples from contamination. Since the recovery of DNA from artifacts is only in its infancy, scientists are continuing to learn the environments, materials, and contexts that allow DNA to survive in archaeological contexts. A simple and effective rule is to treat any personal artifact that potentially came into contact with human body fluids or was inserted into an orifice as a potential carrier of human DNA. Examples of personal artifacts include pipe stems, mouthpieces from musical instruments, irrigators, syringes, and false teeth.

It is also important to have on hand a sterile DNA sample kit that includes paper envelopes and bags, forceps, writing utensils, latex gloves, and face masks. One person on the site should be respo nsible for the recovery of the artifacts, thereby eliminating multiple potential contaminant contributors. Recovery of several artifacts requires new gloves and forceps for each artifact, regardless of contextual association. Additional precautions include collection of DNA samples from all archaeologists who may have come into contact with the objects. If the forensic laboratory personnel suspect contamination of a sample, the archaeologists can be quickly eliminated as contributors through the analysis of a simple cheek swab.

In addition to contamination of the sample through handling by archaeologists or forensic laboratory personnel, samples can be cross contaminated or contaminated by chemicals and carryover by laboratory products used to identify degraded or altered DNA (Hummel 2003:133). Although archaeologists have little control over the latter two, they can help reduce sample contamination by choosing a DNA laboratory that meets forensic investigation standards. The elimination of cross contamination is accomplished by ensuring that the laboratory handles artifact samples separately and adheres to strict "DNA clean" procedures for all equipment. Typically, forensic laboratories eliminate chemical and product carry over by separating the pre- and postamplification equipment in separate rooms (Hummel 2003:133). The final way to ensure credibility of the recovery 
of degraded DNA is to repeat the experiment, preferably by different personnel or in a different laboratory, or both.

\section{STR and PCR: Breaking Down DNA}

Preservation, degradation, and diagenesis inevitably affect and may transform DNA, making its recovery much more difficult than the extraction of DNA from living organisms (Herrmann and Hummel 1994:1-2). Despite this challenge, archaeologists should not be discouraged since degraded forms of DNA can be resuscitated.

Today's procedures extract, amplify, and profile residual DNA from historic objects. Using short tandem repeat (STR) analysis, it is possible to determine the sex, genetic profile, and the number of individuals in contact with an artifact. STRs are polymorphic DNA loci, or areas on the chromosome, that contain a repeated nucleotide sequence. The number of repeat units at an STR locus is highly variable, and many loci are known. The repeating unit is usually from two to seven nucleotides in length. Often referred to as the building blocks of DNA, the four nucleotides are the variable units in the nucleic acid chain, and the sequence in which they occur is the basis of genetic similarity and difference (Rudin and Inman 2001:211). Such polymorphic STR loci are therefore very useful for human identification purposes (Edwards et al. 1992). For example, STRs allow the identification of particular alleles at certain loci on the chromosome, which helps determine the number of individuals, sex, and perhaps population group affiliated with a particular sample.

In order to extract such data from DNA molecules, forensic scientists amplify the STR loci using the polymerase chain reaction (PCR) process. During the middle 1980s, the invention of the PCR technique provided a means of identifying degraded or altered DNA (Mullis and Faloona 1987; Herrmann and Hummel 1994:8; Jones 2001:17-18). The family of DNA polymerase enzymes plays a crucial role in replication and repair of damaged double helices in living, growing organisms by copying single strands of DNA to make double-stranded DNA. Once this enzyme's DNA replication duties were harnessed, it became possible to amplify tiny, incomplete fragments of genetic material, such as samples from archaeological contexts, because the PCR technique only required traces of the original nucleic acid to produce the numerous copies required to achieve accurate genotyping analysis. Additionally, PCR-based tests have now been standardized and automated to meet criminal forensic standards, ensuring reproducible results (PE Applied Biosystems 1998).

\section{Race vs Ancestry}

A well-preserved DNA sample can yield a series of alleles at known loci on the chromosome and, in turn, identify a person on the basis of his/her unique combination. In the last several years, forensic scientists have begun to examine DNA databases to determine whether frequencies of alleles or rare allele variants at known loci on the chromosome are associated with certain population groups (Budowle et al. 1999; Budowle et al. 2001), which include traditional, albeit problematic, categories such as African American, Asian, Caucasian, Hispanic, and Native American. Although described as "population groups," such categories clearly refer to the race concept. It is important to realize that ambiguous terms such as race crudely categorize the reality of human culture and genetic diversity and should be used with caution (American Anthropological Association 1999; Brace and Seguchi 2002).

Despite the shortcomings of the term, forensic scientists continue to rely on racial identities in the national DNA databanks used to assist with crime investigation. Although the genetic variation within traditional conceived races is much greater than that between them, differences exist in the frequencies with which certain genetic variants occur in populations of differing biogeographic ancestry (Bamshad et al. 2003).

Since its invalidity as an absolute category is guilty as charged, the race concept, along with its loaded implications, clearly remains a category of tremendous significance for historical archaeologists and forensic scientists alike (Mays 1998; Rhine 1998; Orser 1999, 2001). Research on population groups continually inspires questions about the ancestral origins of people who used artifacts unearthed by archaeologists. In some cases, an artifact harboring genetic material with identifiable rare allele variants may provide molecular data that point to the ancestral 
background of someone who came into contact with that object (Schablitsky, this volume).

While this discussion of the race concept and its association with forensic studies may raise some concerns, it is not an attempt to legitimize that concept. Rather, it offers one part of a complex solution to pan-anthropological efforts to purge the race concept. Through both the acknowledgment and condemnation of the socially constructed term, archaeologists, along with forensic and genetic anthropologists, can begin to educate a broad audience by substituting the term ancestry for race. Reference to a person's or group's ancestry allows anthropologists to use a descriptor that recognizes genetic and cultural differences expressed by individuals throughout the world.

\section{Article Summaries}

The first set of articles within this volume underscore the utility of nuclear and mitochondrial DNA tests at historical archaeological sites. The extraction and interpretation of nuclear DNA from personal artifacts introduced historical archaeologists to the new specialty of genetic archaeology. Julie Schablitsky describes various forensic tests on a glass hypodermic syringe and associated needles unearthed from a 19th-century home in the mining West. Using all applicable forensic technology available in the laboratory, the syringe underwent DNA extraction procedures and a gas chromatograph mass spectrometer (GC/MS) test for opiates. By interpreting the archaeological site in conjunction with DNA results, she demonstrates how genetic information altered preliminary artifact associations and illuminated a previously unrealized past.

Exploring the applicability of genetic archaeology to different sites and artifacts, Kelly J. Dixon's article overviews the ways in which the GC/MS and genetic analyzer retrieved biological evidence from artifacts recovered from the ruins of a 19th-century African American saloon in a northern Nevada boomtown. The GC/MS results identified leftovers from a meal, a discovery that reminds archaeologists to be wary of cleaning certain artifacts, as they may contain microscopic information that can deepen understandings of material data. DNA tests on a tobacco pipe stem demonstrated that it is possible to determine whether a man or a woman used an otherwise genderless artifact. This, Dixon argues, is grounds for making more meaningful, gender-based interpretations that are based soundly upon unequivocal, forensic evidence.

While Schablitsky and Dixon concentrate on the retrieval of nuclear DNA from artifacts, Mark D. Leney's essay focuses on the recovery of mtDNA from bones and teeth using human remains associated with forensic archaeological casework from various parts of the world and from a range of environments. Leney describes which parts of the human body are most conducive for the recovery of mtDNA and discusses ways to avoid contamination of the bone samples. This invaluable study of historical skeletal material in various environments will no doubt direct the collection of future DNA samples.

Douglas W. Owsley, Brooks B. Ellwood, and Terry Melton combine traditional crime scene investigation using remote sensing, archaeological methods, human osteology, and mtDNA testing to locate and identify the 125-year-old skeleton of Texas gunslinger William Preston Longley. The article first introduces readers to the complicated process of locating an unmarked grave and then determining from skeletal remains the sex, age, and stature of the individual in question. The authors also effectively incorporate material and historic records, such as the report of a corsage made of celluloid attached to the lapel of the infamous gunslinger, to assist identification of the purported remains. The scientific team takes the identification one step further by successfully matching the outlaw's mtDNA with a living maternal relative, which ultimately closed the case.

Ground-penetrating radar (GPR) is fast becoming a popular, innovative tool for forensic and archaeological fieldwork. Much of its popularity lies in the fact that it provides a nondestructive means of scanning the subsurface of a site or scene. Lawrence B. Conyers demonstrates how, in addition to GPR's ability to demarcate buried features such as building ruins, it is especially useful in locating unmarked graves.

Although archaeologists are encouraged to apply remote sensing techniques prior to excavating individual burials, occasionally rescueand-recovery projects do not require the technology for the exhumation of an entire cemetery. William D. Stevens and Jonathan M. Leader's article discusses the analysis of 40 Civil War 
era burials, including the first crew of the H.L. Hunley submarine, recovered from beneath the Citadel's Johnson-Hagood Stadium. Osteological analysis revealed skeletal and dental lesions on the remains, shedding light on the sailors' lives and the physical labor they endured while in service. In addition, Stevens and Leader's work can serve as a comparative study for future osteological work associated with individuals from the Civil War era.

The discovery and exhumation of Isaac Newton Mason, a Civil War confederate soldier, provides archaeologists a step-by-step protocol for the study of human remains preserved in cast-iron coffins. Owsley and experts in the historical, archaeological, and forensic fields joined forces to determine the class status, occupation, diet, and vices of Private Mason. In addition to artifact, clothing, historical, and osteological analysis, the team also conducted stable carbon and nitrogen isotope analysis on the bone, radioimmunoassay tests on the hair, and toxicology studies. Results from this collaborative research not only provide a glimpse into a southern soldier's lifestyle but also offer a view into the trials and travails of transporting deceased family members to their homes after battle.

While some scientists concentrate on how people lived, Thomas A. Crist's research focuses on how people died. Zeroing in on bone damage to illuminate differences between postmortem damage and bullet wounds, he ultimately challenges previous findings on early19th-century gun culture. Specifically, Crist compares historic documentation on trauma to minorities with secondary histories of gun possession. He subsequently encounters obvious contradictions between one historian's views about the gun culture and archaeologists' frequent encounters with bone damage from bullet wounds. Crist's findings boldly underscore the necessity of using archaeological data in concert with historic documents to accurately interpret the past.

Moving from bullet wounds to the weapons fired to inflict such injuries, Kent P. Weber and Douglass D. Scott study microscopically the subtle markings on percussion caps to trace the progression of an historic battle. Treating the battlefield as a crime scene, Weber and Scott reproduce and analyze percussion caps to iden- tify the number, type, and movement of weapons, ultimately re-creating an historic event. In order to encourage other archaeologists to apply this same innovative approach, the authors test and verify their findings using the percussion-cap identification method on an unknown collection, proving its fail-safe applicability to other archaeological sites.

\section{Just Ask the Question}

Forensic science often calls upon archaeology to establish proper provenience and standards of evidence recovery from crime scenes. While archaeologists help and even participate in such investigations, they do not tend to apply forensic methods to archaeological sites as much as they could-and should. An interdisciplinary, reciprocal potential exists for these two disciplines to prosper in tandem. The diverse studies displayed in this volume provide examples of proven scientific and biomedical methods and techniques available to archaeologists.

Over the last decade, forensic applications in many scientific fields have advanced DNA research, lowered laboratory costs, and raised standards (Handt et al. 1994). With the growth of such technologies comes a certain inflexibility that could frustrate archaeologists. For example, most forensic applications are focused largely on individuation of human remains or human residues. Instead, archaeologists may be more interested in answering questions about nonhuman biological materials, such as foodstuffs, artifacts, or commensal species. As archaeologists become increasingly familiar with the fundamental technologies involved, they will likely find that variations and modifications of certain forensic techniques will adequately address archaeological questions in ways that the molecular biologists have not yet conceived. It is, then, up to archaeologists to raise questions that inspire experimentation and innovation related to the recovery of DNA. The application of forensic technology to historic sites will drive forward the development of molecular archaeology while helping reduce the ambiguous interpretations that too often plague historical archaeology.

While forensic anthropology is driven by questions posed by the legal system, historical archaeology is driven by a variety of research 
questions, many of which center upon producing a humanistic understanding of the past. In addition to historical records and physical remains, the recovery of biological evidence from the archaeological record provides yet another dataset for archaeologists. Each of the studies outlined herein is testament to the diversity of techniques available to forensic scientists and now to historical archaeologists.

\section{References}

\section{American Anthropological Association}

1999 American Anthropological Association Statement on Race. American Anthropologist 100(3):712-713.

Bamshad, Michael J., Stephen Wooding, W. Scott Watkins, Christopher T. OstLer, Mark A. BAtzer, AND LYNN B. JORDE

2003 Human Population Genetic Structure and Inference of Group Membership, American Journal of Human Genetics 72(3):578-589.

Brace, C. Loring, and Noriko Seguchi

2002 "Race" Is Not a Valid Biological Concept. Paper presented at Inter-Congress of the International Union of Anthropological and Ethnological Sciences, September 22-27, Tokyo, Japan.

Budowle, Bruce, Tamyra R. Moretti, Anne L. Baumstark, Debra A. Defenbaugh, and Kathleen M. KEYS

1999 Population Data on Thirteen CODIS Core Short Tandem Repeat Loci in African Americans, U.S. Caucasians, Hispanics, Bahamians, Jamaicans, and Trinidadians. Journal of Forensic Sciences 44(6):1277-1286.

Budowle, Bruce, Brendan Shea, Stephen Niezgoda, AND RANAJIT CHAKRABORTY

2001 CODIS STR Loci Data from 41 Sample Populations. Journal of Forensic Sciences 46(3):453-489.

Cleland, Charles E.

2001a Historical Archaeology Adrift? Historical Archaeology 35(2): $1-8$.

2001b Reply to Douglas V. Armstrong, Lu Ann De Cunzo, Gregory A. Waselkov, Donald L. Hardesty, and Roberta S. Greenwood. Historical Archaeology 35(2):28-30.

Connor, Melissa, and Douglas D. Scott (editors)

2001 Archaeologists as Forensic Investigators: Defining the Role. Historical Archaeology 35(1).

Delle, James A.

1999 The Landscapes of Class Negotiation on Coffee Plantations in the Blue Mountains of Jamaica: 1790-1950. Historical Archaeology 33(1):136-158.
Edwards, A., H. A. Hammond, J. Lin, C. T. Caskey, and

R. Chakraborty

1992 Genetic Variation at Five Trimeric and Tetrameric Tandem Repeat Loci in Four Human Population Groups. Geneomics 12:241-253.

Handt, O., M. Richards, M. Trommsdorf, C. Kilger, J. Simanainen, O. Georgiev, K. Bauer, A. Stone, R. Hedges, W. Schaffner, G. Utermann, B. Sykes, and S. PAABO

1994 Molecular Genetic Analyses of the Tyrolean Ice Man. Science 264: 1774-1778.

Herrmann, Bernd, and Susanne Hummel (editors)

1994 Ancient DNA: Recovery and Analysis of Genetic Material from Paleontolgical, Archaeological, Museum, Medical, and Forensic Specimens. SpringerVerlag, New York, NY.

Hummel, SusAnNe

2003 Ancient DNA Typing: Methods, Strategies, and Applications. Springer-Verlag, Berlin, Germany.

Jones, MarTin

2001 The Molecule Hunt: Archaeology and the Search for Ancient DNA. Arcade Publishing, New York, NY.

MAYS, SIMON

1998 The Archaeology of Human Bones. Routledge, New York, NY.

Monsalve, M. Victoria, Anne C. Stone, Cecil

M. Lewis, Allan Rempel, Michael Richards, Dan

Stratthof, and Dana V. Devine

2002 Brief Communication: Molecular Analysis of the Kwäday Dän Ts'ìnchi Ancient Remains Found in a Glacier in Canada. American Journal of Physical Anthropology 119(3):288-291.

Mullis, Kary B., and F. A. Faloona

1987 Specific Synthesis of DNA in Vitro via a Polymerase Catalyzed Chain Reaction. Methods in Enzymology 155:355-50.

Orser, Charles E., JR. (EDitor)

1999 The Challenge of Race to American Historical Archaeology. American Anthropologist 100(3): 661-668.

2001 Race and the Archaeology of Identity. University of Utah Press, Salt Lake City.

PE APPLIEd Biosystems

1998 AmpF STR $®$ Profiler Plus PCRAmplification Kit User's Manual. Perkin Elmer Applied Biosystems.

Praetzellis, AdRian

2000 Death byTheory: ATale of Mystery and Archaeological Theory. AltaMira Press, Walnut Creek, CA.

Rhine, STANLEy

1998 Bone Voyage: A Journey in Forensic Anthropology. University of New Mexico Press, Albuquerque. 
Rudin, Norah, AND KeITH INMAN

2001 An Introduction to Forensic DNA Analysis, 2nd edition. CRC Press, Washington, DC.

Julie SCHABLITSKY

Museum of Natural and Cultural History

1224 UNIVERSITY OF OREGON

EugENE, OR 97403-1224

Kelly J. DiXon

Department of Anthropology

UNIVERSITY OF MONTANA

Missoula, MT 59812-0001
Mark D. LeNEY

Central IDENTIFICATION Laboratory Joint POW/MIA Accounting Command 310 Worcester Ave., Bldg. 45

Hickam Air Force Base, HI 96853 